\title{
PENGARUH PENERAPAN SISTEM TANAM LEGOWO TERHADAP BUDIDAYA PADI SAWAH DI KECAMATAN KAMPUNG MELAYU KOTA BENGKULU
}

\author{
THE EFFECT OF APPLICATION OF LEGOWO PLANT SYSTEMS ON "PADI SAWAH" \\ CULTIVATION IN KECAMATAN KAMPUNG MELAYU, BENGKULU CITY
}

\author{
Evi Andriani (1), Melan Ernawati Lubis (1) \\ (1) Program Studi Agribisnis Fakultas Pertanian, Universitas Dehasen Bengkulu) \\ Email : andriani071085@gmail.com
}

\begin{abstract}
ABSTRAK
Penelitian ini bertujuan Untuk mengetahui Pengaruh Penerapan Sistem Tanam Legowo terhadap Budidaya Padi Sawah di Kecamatan Kampung Melayu Kota Bengkulu dan (2). Untuk mengetahui faktor-faktor apa saja yang mempengaruhi pengaruh penerapan sistem tanam Legowo terhadap budidaya padi sawah di Kecamatan Kampung Melayu Kota Bengkulu. Penelitian ini dilaksanakan pada bulan Oktober sampai dengan November 2017 di Kecamatan Kampung Melayu Kota Bengkulu, dengan pertimbangan petani padi sawah pada desa ini telah mengunakan sistem legowo. Dari penelitian ini dihasilkan Pengaruh penerapan teknologi budidaya padi sawah sistem legowo berada pada rata-rata 56,03. Kondisi ini menunjukkan bahwa tingkat penerapan teknologi berada pada kategori tinggi, hasil penelitian menunjukkan rata-rata petani sudah menerapkan teknologi legowo secara baik dalam usahatani padi sawahnya. Hasil analisis regresi linear berganda antara umur, pengalaman, pendidikandan luas lahan ,sebagai variabel independent terhadap tingkat adopsi teknologi legowo. Hasil F-test menunjukkan variabel independent secara bersama-sama berpengaruh terhadap variabel dependent. Namun secara parsial (individu) dari ke 4 (empat) variabel ini, diketahui bahwa hanya pendidikan yang berpengaruh terhadap pengaruh penerapanteknologi legowo, selebihnya yaitu umur, pengalaman dan luas lahan tidak berpengaruh secara parsial (individual).
\end{abstract}

Kata Kunci : tanam legowo, budidaya, padi sawah

\section{ABSTRACT}

This study aims to determine the effect of the application of the Legowo Planting System on Rice Paddy Cultivation in the Bengkulu City Kampung Melayu District and (2). To find out what factors influence the influence of the application of the Legowo cropping system on lowland rice cultivation in the Kampung Melayu Subdistrict, Bengkulu City. This research was conducted from October to November 2017 in Kampung Melayu Subdistrict, Bengkulu City, with consideration of the paddy rice farmers in this village using the Legowo system. From this research, the effect of the application of legowo paddy rice cultivation technology is at an average of 56.03. This condition shows that the level of application of technology is in the high category, the results of the study show that the average farmer has applied legowo technology well in his rice farming. The results of multiple linear regression analysis between age, 
experience, education and land area, as independent variables on the level of legowo technology adoption. The results of the F-test show that the independent variables have an effect on the dependent variable. But partially (individually) from these 4 (four) variables, it is known that only education has an effect on the effect of the application of legowo technology, the rest of which are age, experience and land area do not affect partially (individually).

Keywords : legowo plant, cultivvation, padi sawah

\section{PENDAHULUAN}

Produktivitas padi di Kecamatan Kampung Melayu beberapa tahun ini tidak stabil yaitu produktivitas masih dibawah 100 kwintal per hektar yaitu 38,06 kwintal per hektar. Hal ini disebabkan oleh gangguan dari hamadan penyakit, kemudian dikarenakan banyak penduduk tidak memiliki akses terhadap sumber produksi pangan, terutama tanah dan pendapatan yang cukup. Salah satu upaya yang dapat dilakukan adalah dengan penyediaan pangan yang cukup, melalui peningkatan produksi pertanian (Profil Desa, 2016).

Usaha peningkatan produksi pertanian salah satunya diwujudkan dengan pemberian pengetahuan dan keterampilan penggunaan teknologi (inovasi) pertanian modern (Eko, 2011). Namun, kenyataannya lebih banyak penolakandari berbagai pihak terhadap inovasi baru yang diperkenalkan pada mereka. Alasan karena inovasi tersebut dianggap telah bertentangan dengan adat dan kebiasaan selama ini.Kasus seperti ini memberikan lebih banyak informasi, bahwa yang pertama-tama harus diubah adalah mentalitas petani itu sendiri agar mereka lebih mudah menerima pembaharuan dan mengadopsi inovasi teknologi dalam bidang pertanian sebagai strategi petani untuk meningkatkan produksi dan pendapatan dari usahatani padi (Redfield, 2002).

Budidaya padi sawah merupakan salah satu warisan budaya nenek moyang sejak ribuan tahun lalu.Hingga kini budidaya tanaman padi tersebut masih terus dilakukan di Indonesia, bahkan dikembangkan guna mencukupi kebutuhan pangan. Namun produksi padi bersifat fluktuatif, salah satunya terlihat dari produktivitas yang mengalami penurunan pada tahun 2000-an sampai sekarang. Untuk itu diperlukan usaha-usaha yang maksimal dalam peningkatan produksi pertanian tersebut (Fagi, 2009).

Salah satubentuk teknologi di sektor pertanian untuk mengatasi permasalahan tersebut adalah dengan cara memperbaiki cara bertaniyang salah satunya 
adalah menerapkan inovasi sistem tanam Legowo yang merupakan pengembangankonsep terpadu yang dipelopori oleh BPTP. Sistem tanam legowo mempunyai beberapa keunggulan antara lain adalahdapat mengendalikan populasi hama tikus, wereng coklat, produktivitas tanamanlebih tinggi, pemeliharaan lebih mudah dan membutuhkan benih yang lebihsedikit. Selain itu sistem tanam Legowo juga digunakan dalampembudidayaan padi yang digunakan untuk benih unggul

Tujuan yang ingin dicapai pada penelitian adalah (1). Untuk mengetahui Pengaruh Penerapan Sistem Tanam Legowo terhadap Budidaya Padi Sawah di Kecamatan Kampung Melayu Kota Bengkulu dan (2). Untuk mengetahui faktor-faktor apa saja yang mempengaruhi pengaruh penerapan sistem tanam Legowo terhadap budidaya padi sawah di Kecamatan Kampung Melayu Kota Bengkulu.

\section{METODE PENELITIAN}

\section{Tempat dan Waktu}

Penelitian ini dilaksanakan pada bulan Oktober sampai dengan November 2017 di Kecamatan Kampung Melayu Kota Bengkulu, dengan pertimbangan petani padi sawah pada desa ini telah mengunakan sistem legowo.

\section{Jenis dan Sumber Data}

Data yang digunakan dalam penelitian ini adalah data primer dan data sekunder. Data primer diperoleh dari hasil wawancara langsung dengan masyarakat yang dijadikan responden dengan menggunakan kuisioner. Data sekunder diperoleh dari Kecamatan Kampung Melayu Kota Bengkulu.

\section{Pengambilan Sampel}

\section{Populasi}

Populasi dalam penelitian ini adalah petani di Kecamatan Kampung Melayu Kota Bengkulusebanyak 124 yaitu yang melakukan sistem tanam legowo.

\section{Sampel}

Pengambilan sampel penelitian ini dilakukan dengan metode simple random sampling yaitu sampel yang diambil sedemikian rupa sehingga setiap unit populasi mempunyai kesempatan yang sama untuk dipilih sebagai sampel (Suyanto, 2008).

\section{Metode Analisis Data}

Untuk menjawab beberapa tujuan yang diajukan dalam penelitian ini, maka 
data penelitian dianalisis melalui cara-cara

berikut:

1.Pengaruh teknologi padi sawah sistem legowo

$$
\begin{aligned}
& \text { Interval }=\frac{\text { nilai atas }- \text { nilai bawah }}{\text { Jumlah kelas }} \\
& \text { Interval }=\frac{75-15}{3}=20
\end{aligned}
$$

Dimana : nilai atas : skor tertinggi (5) $\mathrm{x}$ Jumlah pertanyaaan, nilai bawah :skor terendah (1) x Jumlah pertanyaan

Kategori :Rendah :15 - 35, Sedang : 36 55, dan Tinggi :56 - 75

2.Faktor-faktor yang mempengaruhi

Untuk mengetahui faktor-faktor yang mempengaruhi mempengaruhi pengaruh penerapan sistem tanam Legowo terhadap budidaya padi sawah, dengan menggunakan analisis regresi linear berganda (Novriani, 2010) :

$$
Y=a+b_{1} X_{1}+b_{2} X_{2}+b_{3} X_{3} . b_{4} X_{4} \ldots . .+e
$$

Keterangan : Y : Variabel terikat, $a$ : Konstanta, $b_{1}$, $\mathrm{b}_{2} \ldots \mathrm{b}_{4}$ : Koefisien dari $\mathrm{X} 1, \mathrm{X} 2$ dan $\mathrm{X} 3, \mathrm{X}_{1}, \mathrm{X}_{2} \ldots \mathrm{X}_{4}$ : Variabel bebas, e: Kesalahan pengganggu

Untuk mengetahui apakah variabelvariabel bebas secara keseluruhan bersamasama berpengaruh terhadap variabel terikat pada tingkat keperluan tertentu maka dilanjutkan uji-F pada taraf kepercayaan 95\%. Uji-F dapat dirumuskan sebagai berikut (Siegel, 1998 dalam Novriani, 2010) :

$$
F=\frac{R^{2}(k-1)}{\left(1-R^{2}\right) /(n-k)}
$$

Keterangan $: \mathrm{R}^{2}$ : koefisien determinasi, $\mathrm{k}$ : jumlah variabel yang diamati (dependen dan variabel independent), $\mathrm{n}$ : Jumlah Sampel

Adapun kriteria uji-F adalah sebagai berikut :

1.Jika $\mathrm{F}_{\text {hitung }}>\mathrm{Ft}_{\text {tabel }}$ maka tolak Ho dan terima $\mathrm{Ha}$, artinya secara bersama-sama variabel bebas berpengaruh terhadap variabel terikat.

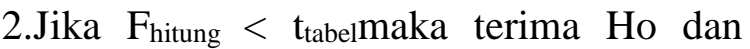
tolak Ha, artinya secara bersama-sama variabel bebas tidak berpengaruh terhadap variabel terikat.

Untuk mengetahui pengaruh masing-masing variabel bebas terhadap variabel terkait ditentukan uji-t dengan hipotesis sebagai berikut(Siegel, 1998 dalam Novriani, 2010) : Ho : bi = 0, Hi : bi $>0$ atau bi $<0$

\section{bi}

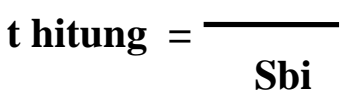

Dimana : bi : Koefisien Variabel Xi, I: 1, 2, 3, Sbi: Kesalahan baku koefisien bi Adapun kriteria pengujiannya adalah sebagai berikut : 
a.Jika $t_{\text {hitung }}>t_{\text {tabel }}$, atau $-t_{\text {hitung }}<-t_{\text {tabel }}$ maka tolak Ho dan terima $\mathrm{Ha}$, artinya secara individu variabel bebas berpengaruh terhadap variabel terikat.

Jika $t_{\text {hitung }}<\mathrm{t}_{\text {tabel}}$, atau $-\mathrm{t}_{\text {hitung }}>-\mathrm{t}_{\text {tabel }}$ maka terima Ho dan tolak $\mathrm{Ha}$, artinya secara individu variabel bebas tidak berpengaruh terhadap variabel terikat.

\section{HASIL DAN PEMBAHASAN}

Pengaruh Penerapan Teknologi

Budidaya Padi Sawah Sistem Legowo

Tingkat penerapan teknologi budidaya padi sawah sistem legowodi Desa Padang Serai Kecamatan Kampung Melayu Kota Bengkulu disajikan pada tabel 1.
Pada tabel 1 dapat dilihat bahwa rata-ratapengaruh penerapan teknologi budidaya padi sawah sistem legowo berada pada rata-rata 56,03.Kondisi ini menunjukkan bahwa pengaruh penerapanteknologi dengan kategori tinggi, dimana berdasarkan hasil penelitian ratarata petani sudah menerapkan teknologi legowo secara baik dalam usahatani padi sawahnya.Sebaran pengaruh penerapanteknologi budidaya padi sawah sistem legowo di Desa Padang Serai Kecamatan Kampung Melayu Kota Bengkulu disajikan pada tabel 2.

Tabel 1.Pengaruh Penerapan Teknologi Budidaya Padi Sawah Sistem Legowo

\begin{tabular}{|c|l|c|c|}
\hline No & \multicolumn{1}{|c|}{ Kategori (skor) } & Rata-rata & Tingkat Kinerja \\
\hline 1 & Rendah $=15-35$ & 56,03 & Tinggi \\
2 & Sedang $=36-55$ & & $56-75$ \\
3 & Tinggi $=56-75$ & & \\
\hline
\end{tabular}

Sumber: Data Primer diolah, 2017

Tabel 2. Distribusi Pengaruh Penerapan Sistem Legowo

\begin{tabular}{|l|l|c|c|}
\hline No & \multicolumn{1}{|c|}{ Kelas Adopsi } & Jumlah (jiwa) & Persen (\%) \\
\hline 1 & Rendah $=15-35$ & 4 & 12,90 \\
2 & Sedang $=36-55$ & 7 & 22,58 \\
3 & Tinggi $=56-75$ & 20 & 64,51 \\
\hline & Jumlah & 31 & 100 \\
\hline
\end{tabular}

Sumber: Data Primer diolah, 2017 
Dari Tabel 2, terlihat bahwa pengaruh penerapanteknologi budidaya padi sawah sistem legowo kinerja penyuluh pertanian yang paling banyak adalah kelas antara 56 - 75 yaitu dengan kategori tinggi dengan jumlah 20 orang atau 64,51\%. Sedangkan pengaruh penerapan teknologi budidaya padi sawah sistem legowopaling sedikit antara 15 - 35 yaitu dengan kategori rendah, berjumlah 4 orang atau $12,90 \%$. Rata-ratapengaruh penerapanteknologi budidaya padi sawah sistem legowo adalah 56,03dengan kategori tinggi. Untuk lebih jelas dapat dilihat pada grafik 1.

Tingginya pengaruh penerapan budidaya padi sawah sistem legowodiartikan bahwa petani padi sawah sudah menerapkan teknologi legowo secara baik. Hal ini dikarenakan petani masih yakin dengan teknologi legowo dapat meningkatkan pendapatan keluarganya.
Karena teknologi budidaya padi sawah sistem legowo dapat mengurangi hama tanaman, khususnya hama tikus dan meningkatkan produksi hasil panen padi.

Berdasarkan hasil penelitian yang dilakukan oleh Diratmaja (2013) bahwa di Kabupaten Sukabumi, pendapatan usahatani padi dengan menerapkan sistem tanam jajar legowo lebih besar dibandingkan dengan sistem tanam tegel yaitu sebesar $\mathrm{Rp}$ 5.192.600 ha $^{-1}$ per musim tanam, sementara itu pendapatan petani padi dengan menggunakan sistem tanam tegel sebesar Rp 4.180.500ha-1 per musim tanam dengan nilai net $\mathrm{B} / \mathrm{C}$ yang di peroleh pada usahatani sistem tanam jajar legowo sebesar 1,78 dan pada sistem tanam tegel sebesar 1,54. Nilai pendapatan yang tinggi dikarenakan oleh tingginya jumlah produksi gabah yang dihasilkan dibandingkan dengan sistem tanam tegel (Dewi, 2014).

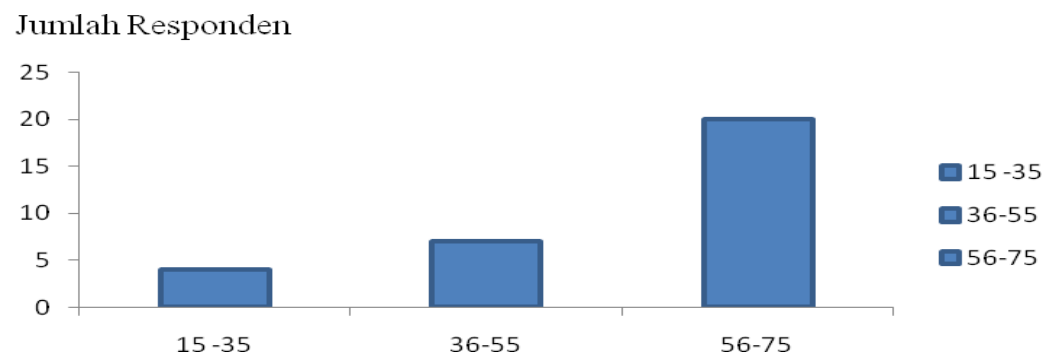

Gambar.1. Grafik Penerapan Teknologi Budidaya Padi Sawah Legowo 
Faktor-Faktor yang Mempengaruhi penerapan Teknologi

Output SPSS pada tabel 3 menunjukkan p-value (0.000) lebih kecil dari level of significant yang ditentukan (0.05), artinya signifikan. Sedangkan F hitung sebesar 5.518 lebih besar dari $\mathrm{F}$ tabel $2,74($ df $1=5-1=4$ dan df $2=31-5=$ 26), artinya signifikan berarti Ha diterima dan Ho ditolak artinya antara umur, pengalaman, pendidikan, dan dluas lahan, secara bersama-sama berpengaruh terhadaptingkat adopsi teknologi legowo.

Untuk mengetahui seberapa besar kemampuan variabel independen (umur, pengalaman, pendidikan, luas lahan)menjelaskan variabel dependent, secara bersama-sama berpengaruh terhadap terhadap tingkat adopsi teknologi legowo dilakukan uji koefisien determinasi. Dalam Output SPSS, koefisien determinasi terletak pada tabel model summary dan tertulis $R$ Square. Namun untuk regresi linear berganda sebaiknya menggunakan R Square yang sudah disesuaikan (Adjusted $R$ Square) karena disesuaikan dengan jumlah variabel independent yang digunakan dalam penelitian. Nilai Square dikatakan baik jika diatas 0,5 kareana nilai $\mathrm{R}$ Square berkisar antara 0 sampai 1 (Nugroho, 2005). Hasil koefisien determinasi pada output SPSS dapat dilihat pada tabel 4

Tabel 3. ANAVA

\begin{tabular}{|l|c|r|r|r|r|}
\hline \multicolumn{1}{|c|}{ Model } & \multicolumn{1}{c|}{$\begin{array}{l}\text { Sum of } \\
\text { Squares }\end{array}$} & \multicolumn{1}{c|}{ Df } & Mean Square & \multicolumn{1}{c|}{ F } & \multicolumn{1}{c|}{ Sig. } \\
\hline Regression & 1681.358 & 4 & 420.340 & 5.518 & $.002^{\mathrm{a}}$ \\
\hline Residual & 1980.577 & 26 & 76.176 & & \\
\hline Total & 3661.935 & 30 & & & \\
\hline
\end{tabular}

Tabel 4. Pengaruh umur, pengalaman, pendidikan, luas lahan terhada terhadap penerapan teknologi legowo

\begin{tabular}{|l|c|r|r|r|r|}
\hline Model & $\mathrm{R}$ & R Square & Adjusted R Square & Std. Error of the Estimate & Durbin-Watson \\
\hline 1 & $.678^{\mathrm{a}}$ & .459 & .376 & 8.72789 & 1.195 \\
\hline
\end{tabular}

a. Predictors: (Constant), umur, pengalaman, pendidikan, luas lahan

b. Dependent Variable: penerapan teknologi legowo 
Dari hasil estimasi diperoleh nilai koefisien determinasi $\left(\mathrm{R}^{2}\right)$ sebesar 0.459 atau sebesar 45,9\%. Dan sisanya sebesar $54,14 \%$ dijelaskan oleh variabel lain yang tidak ada pada model tersebut. Jadi besarnya pengaruh umur, pengalaman, pendidikan, luas lahan, secara bersamasama sebesar $45,9 \%$.

Berdasarkan hasil analisis regresi linear berganda hasil F-test menunjukkan secara bersama-sama variabel independent berpengaruh terhadap variabel dependent (penerapan teknologi legowo). Untuk melihat hasil analisis estimasi secara bersama-sama dapat disajikan pada tabel 5.

Nilai yang diperoleh dari $\mathrm{F}$ hitung sebesar $(55,518)>$ dari $\mathrm{F}$ tabel $(2,74)$, hal ini mengidentifikasi bahwa secara bersamasama variabel independent (umur, pengalaman, pendidikan, dan luas lahan berpengaruh terhadap variabel dependent yaitu tingkat penerapan teknologi legowo, artinya signifikan berarti Ha diterima dan Ho ditolak.

Tabel 5. Hasil Estimasi

\begin{tabular}{|c|c|c|c|c|c|}
\hline Variabel bebas & Koefisien Regresi & Std. Error & t-hitung & P-value & Ket \\
\hline Constant & 38.221 & 12.151 & 3.145 & 0.004 & \\
\hline Umur (X1) & .246 & .259 & -0.950 & 0.351 & NS \\
\hline Pengalaman (X2) & 0.098 & .422 & 0.231 & 0.819 & NS \\
\hline Pendidikan(X3) & 1.990 & .470 & 4.233 & 0.000 & $*$ \\
\hline Luas lahan(X4) & 2.964 & 5.056 & 0.586 & 0.563 & NS \\
\hline $\mathrm{R}$ & 0.678 & & & & \\
\hline $\mathrm{R}^{2}$ & 0.376 & & & & \\
\hline F-hitung & 5,518 & & & & \\
\hline F-tabel $(5 \%, 4 ; 31)$ & 3.26 & & & & \\
\hline t-tabel $(5 \%)$, df-v & $2 ., 042$ & & & & \\
\hline independent $=26$ & & & & & \\
\hline
\end{tabular}

Keterangan :*: Berpengaruh signifikan NS : Tidak berpengaruh 
Dari hasil estimasi diperoleh nilai koefisien determinasi $\left(\mathrm{R}^{2}\right)$ sebesar 0.459atau sebesar 45,9\%. Hal ini mengidentifikasi bahwa besar kecilnya adopsi teknologi legowo dijelaskan oleh umur, pengalaman, pendidikan, dan luas lahan dan sisanya sebesar sebesar $54,14 \%$ dijelaskan oleh variabel lain yang tidak ada pada model tersebut.

Untuk mengetahui lebih khusus pengaruh variabel independen yang mana yang mempengaruhi tingkat adopsi teknologi legowo, maka dapat dilakukan dengan menggunakan uji parsial terhadap kefisien regresi. Pengaruh masing-masing variabel independen terhadap variabel dependent tersebut disajikan dalam tabel 6 .

\section{Umur Petani Padi Sawah}

Hasil analisis secara parsial antaraumur petani padi sawah terhadap tingkatadopsi teknologi legowodiperoleh nilai $t$ hitung lebih kecil $(-0,950)$ dari nilai $t$ tabel (2.04).Hal ini mengakibatkan Ho diterima dan Ha ditolak, artinya adalah tidak terdapat pengaruh yang signifikan antara umur terhadap tingkat adopsi teknologi legowo.Dengan demikian bahwa variabel umur tidak berpengaruh secara signifikan terhadap tingkat adopsi teknologi legowo.Hasil penelitian ini tidak mendukung hipotesis penelitian yaitu umur petani padi sawah berpengaruh terhadap tingkat adopsi teknologi legowo.

Tabel 6. T-hitung

\begin{tabular}{|c|c|c|c|c|c|c|c|}
\hline \multirow[t]{2}{*}{ Model } & \multicolumn{2}{|c|}{ Unstandardized Coefficients } & \multirow{2}{*}{$\begin{array}{c}\text { Standardized } \\
\text { Coefficients }\end{array}$} & \multirow[t]{2}{*}{$\mathrm{t}$} & \multirow[t]{2}{*}{ Sig. } & \multicolumn{2}{|c|}{$\begin{array}{c}\text { Collinearity } \\
\text { Statistics }\end{array}$} \\
\hline & $\mathrm{B}$ & Std. Error & & & & Tolerance & VIF \\
\hline (Constant) & 38.221 & 12.151 & & 3.145 & .004 & & \\
\hline Umur & -.246 & .259 & -.143 & -.950 & .351 & .919 & 1.088 \\
\hline Pengalaman & .098 & .422 & .034 & .231 & .819 & .961 & 1.041 \\
\hline Pendidikan & 1.990 & .470 & .640 & 4.233 & .000 & .910 & 1.099 \\
\hline Luas Lahan & 2.964 & 5.056 & .089 & .586 & .563 & .894 & 1.119 \\
\hline
\end{tabular}


Berdasarkan hasil penelitian umur penyuluh pertanian adalah 37 tahun. Dari hasil penelitian juga umurterlihat tidak berpengaruh signifikan terhadap tingkat adopsi petani pada teknologi budidaya padi sawah sistem legowo. Hal ini disebabkan karena sebagai petani padi sawah, umur seseorang tidak cukup berpengaruh, artinya baik tua maupun muda umur yang dimiliki oleh petani padi sawah dapat menerapkan teknologi legowo, artinya adopsi teknologi legowo dapat diterapkan oleh siapa saja tanpa membedakan umur. Dan mayoritas responden atau petani padi sawah dalam penelitian ini berada pada usia produktif yaitu rata-tata 37 tahun. Hasil penelitian ini sejalan dengan penelitian Herwanto (2002) yang menyatakan bahwa umur petani tidak berpengaruh terhadap kinerja petani sayuran di Desa Sumber Urip Kabupaten Rejang Lebong.

Kemudian hasil penelitian ini jugasejalan dengan hasil penelitian Kusai (1997) yang menjelaskan bahwa variabel umur bukanlah variabel yang menentukan tingkat adopsi teknologi oleh petani ikan. Dijelaskan bahwa sebagian besar petani kan telah cukup lama melakukan usaha budidaya ikan sehingga memiliki waktu yang cukup lama untuk meningkatkan penerapan paket teknologi yang dianjurkan melalui proses difusi.

\section{Lama bekerja (pengalaman) Petani Padi Sawah}

$\begin{array}{lllr}\text { Hasil analisis } & \text { secara } & \text { parsial } \\ \text { (individual) } & \text { antara } & \text { lama } & \text { bekerja } \\ \text { (pengalaman)petani padi } & \text { sawah } & \text { terhadap } \\ \text { tingkat adopsi petani } & \text { pada } & \text { teknologi } \\ \text { budidaya padi } & \text { sawah } & \text { sistem }\end{array}$
legowodiperoleh nilai t hitung lebih kecil $(0,231)$ dari nilai $\mathrm{t}$ tabel (2.04).Hal ini mengakibatkan Ha diterima dan Ho ditolak, artinya terdapat pengaruh yang signifikan antara lamanya bekerja (pengalaman) terhadap tingkat adopsi teknologi legowo.

Pengalaman petani padi sawah dalam melakukan kegiatannya akan dapat memberikan kematangan untuk mengambil keputusan. Semakin lama mereka bekerja maka pengalaman yang dimilikinya semakin banyak pula.Rata-rata pengalaman petani padi sawah adalah 10,92 tahun. Semakin lama petani padi sawah melakukan pekerjaan maka akan semakin banyak pengalaman dan pelajaran yang didapatkan untuk meningkatkan kualitas kerjanya, yang pada akhirnya akan mempengaruhi petanidalam mengambil keputusan. Dari uraian diatas terlihat bahwa sebagian besar petani padi sawah rata-rata mempunyai 
pengalaman yang cukup lama.Dengan pengalaman yang cukup lama, petanisudah memiliki kemampuan dan keterampilan yang relatif tinggi dalam mengembangkan keterampilannya.

Kenyataan dilapangan pengalaman atau lama bekerja tidak berpengaruh secara signifikan terhadap tingkat adopsi petani pada teknologi budidaya padi sawah sistem legowo. Hal ini di karenakan kegiatan usahatani padi dilakukan secara turun temurun, sehingga petani sudah mempunyai konsep atau cara tersendiri dalam berusahatani. Sedangkan teknologi legowo adalah teknologi baru, sehingga petani cenderung tidak langsung menerapkan. Meskipun menerapkan, hanya sebagian dari komponen teknologi legowo yang umum petani gunakan. Hal ini tersebut sejalan dengan hasil penelitian Mulyani (2001) yang menjelaskan bahwa pengalaman berusahatani tidak berpengaruh terhadap tingkat adopsi teknologi, namun ada kemungkinan bahwa tingkat adopsi teknologi ditentukan oleh banyaknya informasi dan pengetahuan tentang teknologi yang dimiliki dan dianggap bermanfaat bagi petani itu sendiri.

\section{Pendidikan Petani Padi Sawah}

Pendidikan merupakan jenjang pendidikan yang ditempuh oleh petani padi sawah. Hasil analisis menyatakan bahwa tingkat pendidikan petani padi sawahberpengaruh signifikan terhadap bahwa tingkat adopsi teknologi legowo dengan nilai t hitung lebih besar (4.233) dari nilai $t$ tabel (2.04) Hal ini mengakibatkan Ho ditolak dan Ha diterima, artinya adalah antara pendidikan petani padi sawah terhadap tingkat adopsi teknologi legowo.

Terdapatnya pengaruh yang signifikan antara tingkat pendidikan terhadap tingkat adopsi teknologi legowodisebabkan karena pendidikan merupakan faktor penunjang bagi keberhasilan seseorang dalam melakukan kegiatan usahanya, karena dengan tingkat pendidikan, akan menambah kemampuan seseorang dalam berpikir, bersikap dan bertindak dalam melaksanakan kegiatan petani padi sawah, artinya semakin tinggi tingkat pendidikan petani padi sawah maka semakin memungkinkan orang tersebut memperoleh tingkat adopsi teknologi legowoyang lebih bagus lagi. Tingginya tingkat pendidikan petani akan membuat mereka semakin mengerti tentang teknologi budidaya padi sawah sistem legowoserta penerapannya dengan baik. 
Rata-rata pendidikan penyuluh pertanian adalah tingkat SMA, yaitu 11,52 atau 12 tahun setingkat SMA, berdasarkan rata-rata tersebut dapat dikatakan sumbangan pendidikan petani padi sawah karena pada umumnya orang yang berpendidikan tinggi akan mempunyai daya pikir yang tinggi, sehingga dalam melakukan pekerjaan bukan hanya mengandalkan tenaga saja. Hasil penelitian ini didukung oleh hasil penelitian Prastika (2013) yang menunjukkan bahwa semakin tinggi tingkat pendidikan, maka semakin tinggi pulakinerja yang diterima oleh penyuluh tersebut.

Kemudian hal ini juga sesuai dengan pendapatan Mardikunto (2003) bahwa pendidikan tinggi akan berpengaruh terhadap tingkat pengetahuan dan keterampilan petani, dimana petani akan berusaha untuk memanfaatkan setiap kesempatan yang dapat memajukan usahataninya. Selain itu beliau juga menjelaskan bahwasemakin tinggi tingkat pendidikan akan menyebabkan petani lebih responsif terhadap adopsi teknologi. Senada dengan pendapatan Soekartawi (2001) yang menjelaskan bahwa pendidikan merupakan faktor penentu tingkat adopsi teknologi, pendidikan yang rendah akan menjadi kendala dalam proses adopsi teknologi baru.
Hasil penelitian ini tidak sesuai dengan pendapat Juita (2005) yang menjelaskan bahwa tingkat pendidikan formal tidak berhubungan nyata dengan tingkat adopsi teknologi. Dijelaskan bahwa hal ini disebabkab karena untuk menerapkan suatu teknologi dalam usahataninya, petani tidak harus memiliki timgkat pendidikan formal yang tinggi. Petani tentunya memiliki keterampilan dan pengetahuan yang berbeda, dimana tidak semua petanki berpendidikan tinggi memiliki keterampilan dan pengetahuan yang lebih tinggi di bandingkan petani yang tingkat pendidikannya rendah.

\section{Luas Lahan}

Luas lahan merupakan keseluruhan luas lahan yang digarap petani dalam berusahatani padi, diukur dalam satuan hektar. Hasil analisis secara parsial (individual) antara luas lahan terhadap tingkat adopsi teknologi legowo diperoleh nilai t hitung lebih kecil $(0,586)$ dari nilai $t$ tabel (2.04). Hal ini mengakibatkan $\mathrm{Ha}$ diterima dan Ho ditolak, artinya adalah tidak terdapat pengaruh yang signifikan antara luas lahan terhadaptingkat adopsi teknologi legowo.

Dari wawancara dan kuisioner yang dilakukan dengan petani padi sawah 
diperoleh rata-rata luas lahan seluas0,59 hektar. Dari rata-rata luas lahan yang dimiliki oleh petani padi sawah yaitu 0,59 adalah tergolong lahan yang sempit. Kenyataan dilapangan bahwa semakin luas lahan yang dimiliki petani maka akan cenderung semakin rendah penerapannya teknologi legowo pada usahataninya. Sebaliknya petani padi sawah yang memiliki lahan yangsempit, akan semakinj mudah untuk menerapkan teknologi legowo yang sesungguhnya.

Hasil penelitian ini sesuai dengan pendapat Sastrawan (2000) yang menjelaskan bahwa petani dengan lahan yang luas belum tentu tingkat adopsinya tinggi dan terjadi adal.ah sebaliknya, karena petani dihantui rasa takut akan terjadinya kegagalan yang berarti malapetaka bagi petani dan keluarganya.

\section{KESIMPULAN}

Pengaruh penerapan teknologi budidaya padi sawah sistem legowo berada pada rata-rata 56,03. Kondisi ini menunjukkan bahwa tingkat penerapan teknologi berada pada kategori tinggi, hasil penelitian menunjukkan rata-rata petani sudah menerapkan teknologi legowo secara baik dalam usahatani padi sawahnya. Hasil analisis regresi linear berganda antara umur, pengalaman, pendidikandan luas lahan ,sebagai variabel independent terhadap tingkat adopsi teknologi legowo. Hasil Ftest menunjukkan variabel independent secara bersama-sama berpengaruh terhadap variabel dependent. Namun secara parsial (individu) dari ke 4 (empat) variabel ini, diketahui bahwa hanya pendidikan yang berpengaruh terhadap pengaruh penerapanteknologi legowo, selebihnya yaitu umur, pengalaman dan luas lahan tidak berpengaruh secara parsial (individual).

\section{DAFTAR PUSTAKA}

Arikunto, Suharsimi. 2006. Prosedur Penelitian Suatu Pendekatan Praktik. Rineka Cipta. Jakarta.

Anggraini, Amelia M, 2014. Jurnal Perspektif Pembiayaan dan Pembangunan Daerah. 2(2) : 12-23

BPTP Bengkulu. 2006.Paket Teknologi Budidaya Padi Sawah Sistem Legowo. $\quad$ bptpbengkulu@litbang.deptan.go.id. Diakses 23 Februari 2007.

Darma, R. 1997. Kajian Tingkat Penerapan Teknologi Pada Uahatani di Lahan Sawah Tadah Hujan. Jurnal Agribisnis Fakultas Pertanian. Unhass. Ujung Pandang.

Dewi. 2014. Analisis Perbandingan Pendapatan Usahatani Padi Sistem Tanam Jajar Legowo Dengan Sistem Tegel Kelurahan Situmekar, Sukabumi. Skripsi.Institut Pertanian Bogor.

Enda, Pratama, Ginting. H. 2016. Evaluasi Terhadap Adopsi Teknologi Sistem 
Tanam Padi Jajar Legowodi Desa Balai Kasih Kecamatan Kuala Kabupaten Langkat.Skripsi. Program Studi Agribisnis. Sumatera Utara. Medan.

Fagi. 2009. Analisis Faktor yang berhubungan dengan tingkat adopsi teknologi usahatani padi dan sumbangan usahatani padi terhadap total penerimaan keluarga petani.Skripsi. Program Studi Agribisnis. Universitas Bengkulu. Bengkulu.

Hajrah, L. 2012. Adopsi Petani Padi Sawah Terhadap Sistem Tanam Jajar Legowo Di Kecamatan Polong Bangkeng Utara, Kabupaten Takalar. Jurnal Sains danTeknologi.12 (3) : 255-264.

Jokolelono, E. 2011.Pangan dan Ketersediaan Pangan. Media Litbang Sulteng IV (2) : 88-96. Jurnal.undat.ac.id.jurnal indek.php.MLS.articles.

Kementrian Pertanian. 2015. Modul Pendampingan Dalam Upaya Khusus Peningkatan Produksi Padi, Jagung, Dan Kedelai. Kementrian Pertanian. Jakarta.

Kusumayanti, IGA. Faktor-faktor yang mempengaruhi kejadian Malnutrisi Pasien Dewasa di Ruang Rawat Inap Rumah Sakit.Jurnal Gisi Klinik Indonesia.

Mardikunto, T. 2004. Bungsu Rampai Pembangunan Pertanian. Sebelas Maret University Press. Surakarta.

Purwoko, A. 2006. Pokok-pokok Pengertian Dalam Penyuluhan Pertanian. Hand out DDPP, Jurusan Sosial Ekonomi Pertanian. UNIB.Bengkulu.

Purwono, Purnamawati, Heni. 2009. Budidaya 8 Jenis Tanaman PanganUnggul. Jakarta: Penebar Swadaya.
Redfield, R. 2002. Masyarakat Petani dan Kebudayaan. CV.Rajawali. Jakarta.

Rista, A.Y. 2016.Tingkat Adopsi Sistem Tanam Jajar Legowo 2:1 Di Kelompok Tani Mina Sri Jaya Desa Sepanjang Kecamatan Glenmore Kabupaten Banyuwangi Jawa Timur.Skripsi. Program Studi Agribisnis. UDAYANA.Bali.

Sembiring, 2015. Padi Sistem Jajar Legowo. https://sekarmadjapahit. wordpress.com/2012/01/30/tanampadi-sistem-jajar-legowo. Diakses tanggal 19 Februari 2017.

Suteja, W. 2003.Adopsi Pertanian Moder dan Dampaknya terhadap Pola Tata Guna Tanah di Desa Dencarik Kecamatan Banjar Kabupaten Bulelang.Prosidang Seminar Nasional Hasil Penelitian Perguruan Tinggi. Buku Kelima. Hal 4.Departemen P dan K Bekerjasama dengan Direktorat Perguruan Tinggi dan Direktorat Pembinaan Penelitian dan Pengabdian kepada Masyarakat. Bogor.

Sugiyono. 2009. Metode Penelitian Pendidikan (Pendekatan Kuantitatif, Kualitatif, dan $R \& D)$ ). Bandung: Alfabeta.

Suyanto, 2008.Metode Penelitian Sosial.Kencana Prenada Media. Indonesia.

Syahrial, A. 2000.Teknologi Shafter Pada Padi Sawah.BPTP.Sukarami.

Wahyunindyawati, Kasijadi F., Heriyanto. 2009. Tingkat Adopsi Teknologi usaha Tani Padi Sawah di Jawa Timur: Suatu Kajian Model Pengembangan "Cooperative Farming. Jurnal Pengkajian danPengembangan Teknologi Pertanian. 6 (1) : 40-49

Widodo. 2004. Faktor-faktor yang berhubungan de ngan Tingkat Adopsi Teknologi Usahatrani 
Jagung Program BRDP (Bengkulu regional Develepment Project) di Desa Teras Terunjam Kecamatan Teras Terunjam Kabupaten Muko Muko. Skripsi. Fakultas Pertanian UNIB. Bengkulu.
Wijayanto. 2012. Faktor-Faktor yang Mempengaruhi Adopsi Teknologi Budidaya Padi Sistem Tanam Jajar Legowo. Balai Pengkajian Teknologi Pertanian Lampung. Lampung. 